\title{
STRATEGI PEMASARAN BALI NYUH GADING VILLA DI KEROBOKAN KABUPATEN BADUNG
}

\author{
Made Adi Krisna Dwipayana \\ Prodi Magister Kajian Pariwisata Universitas Udayana \\ Email : harajuku_cris007@yahoo.co.id
}

\begin{abstract}
The aims of this study is to determine the internal and external factors of strengths, weaknesses, opportunities, and threats of Bali Nyuh Gading (BNG) Villa, North Kuta, Bali, in order to design its appropriate marketing strategy. Respondents in this study are the general manager, director of sales, and finance manager of the villa, because all of these three are the decision maker in the villa. The technique of data analysis used is SWOT analysis and mapped in SWOT diagram. The study shows that the indicator of internal factors which become the strength of BNG Villa for the coming year (2015) is in the indicator of product offered, price, distribution channel, service, physical environment, management process, human resource, organizational structure, net income, and cash flow. The weaknesses is in the promotion indicators. Indicators of external variable which become an opportunities for BNG villa for next year (2015) are the security situation in Bali, government policies, exchange rates, and technology used by the villa. Threats to be faced are local culture and competition between villas. Alternative strategy which should be done is an aggressive strategy with a growth oriented strategy.
\end{abstract}

Keywords: Marketing strategy, BNG Villa and SWOT Analysis

\section{Pendahuluan}

Akomodasi jenis villa berkembang pesat di Bali dalam dua dekade terakhir ini. Selain pertumbuhan hotel konvensional, kehadiran villa ikut memenuhi permintaan akomodasi wisatawan yang berlibur ke Bali. Kalau di hotel konvensional wisatawan merasa tinggal dalam keramaian, pelayanan bersifat 'massal' atau 'kolektif', kalau tinggal di villa mereka bisa merasa situasi yang lebih private dengan pelayanan bersifat personal. Villa bukanlah hal baru dalam dunia akomodasi pariwisata. Villa sudah hadir sebagai sejak tahun 1960-an, sebagai bagian dari hotel konvensional. Beberapa hotel besar, seperti Grand Bali Beach yang berdiri tahun 1966, memiliki beberapa cottagges atau villa, yang lokasinya di luar bangunan utama. Pola villa itu kemudian berkembang menjadi fasilitas akomodasi tersendiri, dikenal 
dengan nama 'villa'.

Suasana berlibur secara private membuat wisatawan lebih nyaman dan juga aman tinggal di villa. Pada umumnya villa memiliki jumlah kamar yang sedikit, jumlah tamu yang sedikit, maka karyawan villa bisa memberikan mereka pelayanan secara kekeluargaan, sehingga wisatawan lebih merasa diperhatikan, dan cenderung merasa lebih nyaman dalam liburannya. Sejak terjadinya serangan terorisme terhadap tempat-tempat yang ramai dan hotelhotel besar yang dikelola jaringan internasional, pilihan menginap di villa semakin meningkat karena dianggap lebih aman dan tidak mungkin menjadi target serangan (Hitchcock dan Putra 2007). Walaupun ini anggapan yang kebenarannya relatif, nyatanya villa-villa semakin favorit sebagai pililhan akomodasi bagi wisatawan yang berlibur ke Bali. Hal ini bisa dilihat dari semakin banyaknya villa berdiri di Bali, seperti di Ubud, Sanur, Nusa Dua, Jimbaran, dan tentu saja Kuta. Di Bali sudah terbentuk organisasi villa yang disebut dengan Bali Villa Association (BVA). Sulit mencari data jumlah villa di Bali karena tidak semua villa sudah mendaftarkan diri sebagai anggota. Dalam web BVA, terdapat dua jenis anggota yaitu authorised member dan associated member. Jumlah anggota yang terdaftar 123 (balivillaassociation.org), jauh sedikit dari bayangan jumlah villa di lapangan.

Perkembangan akomodasi khususnya villa sebagai fasilitas pendukung pariwisata di Bali, menghasilkan devisa yang cukup tinggi dan pertumbuhannya sangat pesat karena banyak wisatawan yang berkunjung, baik wisatawan asing maupun wisatawan domestik. Bali Nyuh Gading Villa (BNG Villa) merupakan perusahaan jasa yang masih relatif baru, secara resmi mulai beroperasi pada bulan April 2006 berdasarkan keputusan Bupati Badung No: 556.D/1209/DIPARDA. Villa ini terletak di kawasan Kerobokan, jelasnya di Jalan Umalas 1 No. 99X Kerobokan dan juga dekat dengan pantai Petitenget.

Banyaknya bermunculan villa di daerah tersebut menyebabkan tingginya tingkat persaingan di antara villa-villa di daerah Kerobokan, sehingga diperlukan strategi pemasaran yang tepat bagi BNG Villa untuk dapat terus menjaga kelangsungan usahanya, dengan cara memaksimalkan sumber daya atau hal-hal yang menjadi kekuatan dan meminimalkan kelemahankelemahannya. Rekomendasi peneliti adalah perlu diterapkannya suatu strategi pemasaran yang efektif, di mana terlebih dahulu harus mengidentifikasikan kekuatan dan kelemahan, peluang dan ancaman agar nantinya dapat meningkatkan volume penjualan dan memenangkan persaingan.

Artikel ini mengangkat tiga masalah. Pertama, faktor-faktor internal apa yang menjadi kekuatan dan kelemahan bagi BNG Villa yang perlu mendapat perhatian bagi manajemen dalam penyusunan strategi pemasaran bagi perusahaan. Kedua, faktor-faktor eksternal apa yang menjadi peluang dan 
ancaman bagi BNG Villa yang perlu mendapat perhatian bagi manajemen dalam penyusunan strategi pemasaran bagi perusahaan. Ketiga, strategi pemasaran apa yang tepat diimplementasikan oleh BNG Villa dengan memperhatikan berbagai faktor, baik faktor internal maupun faktor eksternal perusahaan untuk memenangkan persaingan?

\section{Teori dan Metode}

Teori yang digunakan antara lain manajemen strategi, strategi pemasaran, bauran pemasaran (maketing mix), teori SWOT. Konsep yang digunakan dalam penelitian ini adalah faktor internal, faktor eksternal, pengertian villa.

Teknik pengumpulan data dilakukan dengan menggunakan pedoman wawancara untuk wawancara mendalam, questionnaire (berupa angket yang berisi tentang faktor-faktor internal dan eksternal) dan alat bantu, seperti kamera, dan notes untuk observasi. Teknik analisis data menggunakan analisis kualitatif-kuantitatif yang dibantu dengan analisis SWOT dengan metode Delphi.

\section{Pembahasan}

BNG Villa didirikan pada tanggal 1 April 2006 oleh keluarga besar dr. I Putu Gde Wardhiana, Sp.OG (k). Beliau adalah seorang dokter, yang mencoba untuk membuka usaha yang bergerak di bidang pariwisata, karena melihat peluang bisnis pariwisata di Bali cukup bagus. Lokasi dari BNG Villa adalah di jalan Umalas 1 No.99X Kerobokan dan juga dekat dengan pantai Peti Tenget.

Berikut ini dalam Tabel 1 dapat dilihat jenis dan harga kamar pada BNG Villa sebagai berikut :

Tabel 1 Jenis dan Harga Kamar BNG Villa

\begin{tabular}{cll}
\hline No. & \multicolumn{1}{c}{$\begin{array}{c}\text { Jenis Kamar } \\
\text { (Unit) }\end{array}$} & $\begin{array}{c}\text { Harga Kamar } \\
\text { (Rp.) }\end{array}$ \\
\hline 1. & One Bedroom Deluxe Villa & 900.000 \\
2. & One Bedroom Suite Villa & 1.100 .000 \\
3. & Two Bedroom Deluxe Villa & 1.710 .000 \\
\hline
\end{tabular}

Sumber : Bali Nyuh Gading Villa, 2011

Pada Tabel 1 dapat dilihat harga kamar villa yang berbeda-beda harga tersebut masih bisa berubah sesuai dengan fasilitas yang akan didapatkan. BNG Villa ini segmen pasarnya menggunakan "pemasaran ceruk" (niche market), yaitu pemasaran yang didefinisikan dengan lebih sempit, biasanya memilah suatu segmen menjadi beberapa sub segmen dengan suatu perangkat dan perlakuan yang berbeda yang mungkin mencari suatu kombinasi manfaat yang khusus. Target pasar dari BNG Villa, adalah para wisatawan asing maupun domestik yang berkunjung ke Bali. BNG Villa 


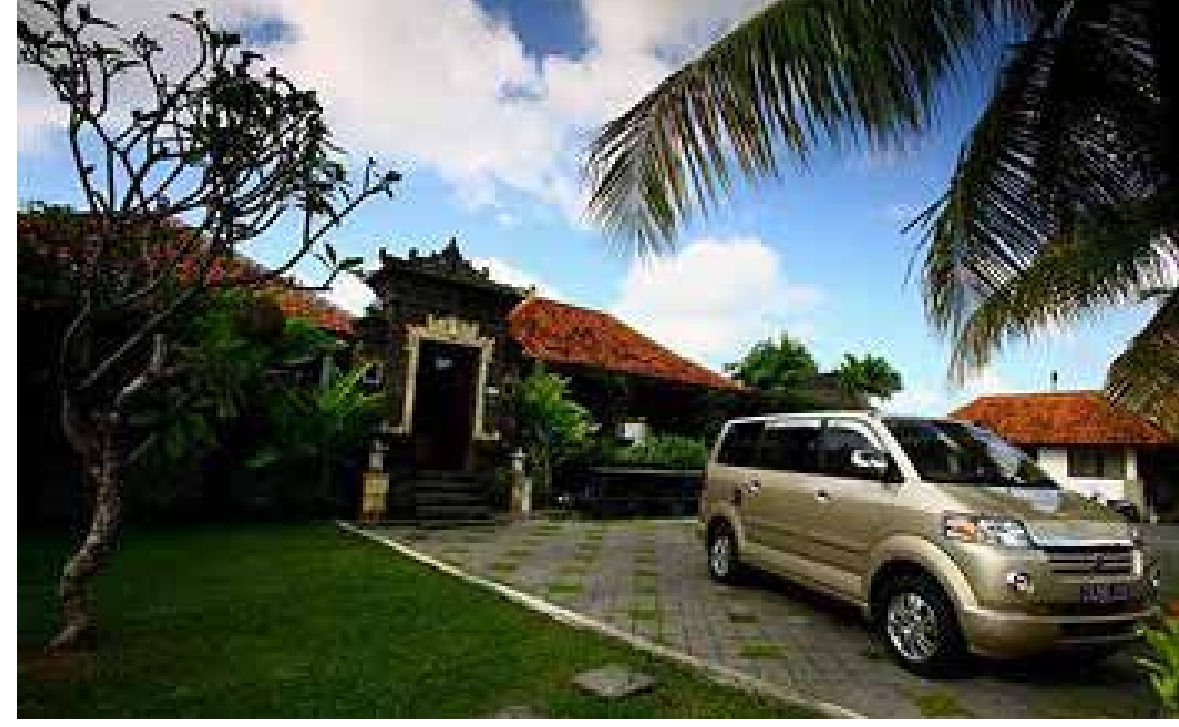

BALI NYUH GADING VILLA

Foto 1. Tampak depan Bali Nyuh Gading Villa

memposisikan produknya pada harga yang kompetitif dengan kualitas dan mutu yang bagus.

Fasilitas lain yang disediakan adalah fasilitas kamar villa yang terdiri dari One Bedroom Deluxe Villa, One bedroom Suite Villa dan Two Bedroom Deluxe Villa; kolam renang pribadi pada setiap villa (private pool); AC (Air Conditioner); TV yang lengkap dengan siaran luar negeri (TV Cable); Kamar mandi dilengkapi dengan bak mandinya; mini bar; Personal Electric Safe Deposit Box; Refrigerator; Coffee maker; Hot and cold water; IDD telephone; dapur dan tempat makan (kitchen and dining area); Kebun (garden view) yang asri dan tertata dengan baik dan sedemikian rupa sehingga sangat menarik.

BNG Villa juga memberikan fasilitas-fasilitas tambahan seperti, fasilitas makanan dan minuman yang dibutuhkan oleh para konsumen; fasilitas mencuci dan menyetrika (laundry); Fasilitas Spa yang bisa didatangkan dari luar; fasilitas pelayanan transportasi atau penyewaan mobil.

\subsection{Kondisi Faktor Internal BNG Villa Tahun 2014 dan Prediksi 2015}

Berdasarkan pengamatan, kondisi faktor Internal BNG Villa Tahun 2014 dan prediksi tahun 2015 adalah di bidang pemasaran, produk yang ditawarkan oleh BNG Villa berupa: kamar villa yang terdiri dari tiga jenis yaitu One Bedroom Deluxe Villa, One bedroom Suite Villa dan Two Bedroom Deluxe Villa; makanan dan minuman yang dibutuhkan oleh pelanggan; kolam renang pribadi pada setiap villa (private pool); fasilitas mencuci dan menyetrika (laundry); fasilitas Spa yang bisa didatangkan dari luar; fasilitas pelayanan transportasi atau penyewaan mobil.

Harga pada BNG Villa adalah harga kompetitif, yaitu harga yang bersaing di pasaran sesuai dengan fasilitas-fasilitas yang disediakan oleh BNG Villa. 


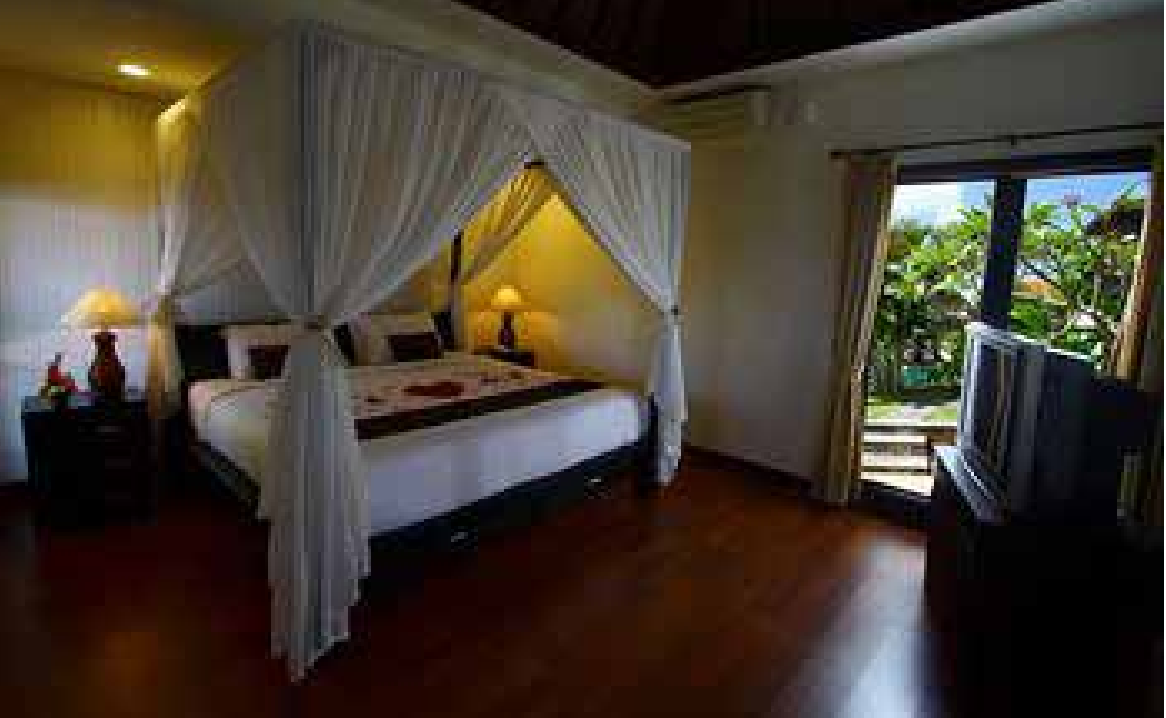

BALI NYUH GADING VILLA

Foto 2. Fasilitas ruangan.

BNG Villa dalam menetapkan kebijakan harga sesuai dengan kondisi pasar dan tidak memperkenankan karyawan untuk menjual harga kamar dibawah tarif minimal, dengan tujuan untuk menjaga image perusahaan agar tetap baik di mata konsumen.

Saluran distribusi yang digunakan oleh BNG Villa adalah menggunakan perantara travel agent ataupun tamu atau konsumen yang akan menginap pada BNG Villa datang sendiri tanpa travel agent. Saluran distribusi sudah cukup efektif namun harus terus ditingkatkan untuk tahun 2015 agar para konsumen merasa puas karena apa yang mereka inginkan bisa dengan cepat didapatkan.

Tabel 2 Tingkat Hunian Kamar BNG Villa Periode Januari - Desember Tahun 2014

\begin{tabular}{lccc}
\hline Bulan & $\begin{array}{c}\text { Jumlah Kamar } \\
\text { Tersedia } \\
\text { (Unit) }\end{array}$ & $\begin{array}{c}\text { Jumlah Kamar } \\
\text { Terjual } \\
\text { (Unit) }\end{array}$ & $\begin{array}{c}\text { Tingkat Hunian } \\
\text { Kamar } \\
(\%)\end{array}$ \\
\hline Januari & 325 & 156 & 48 \\
Februari & 308 & 177 & 57 \\
Maret & 330 & 134 & 41 \\
April & 329 & 57 & 17 \\
Mei & 341 & 133 & 39 \\
Juni & 330 & 162 & 49 \\
Juli & 341 & 224 & 66 \\
Agustus & 341 & 203 & 60 \\
September & 330 & 205 & 62 \\
Oktober & 330 & 197 & 60 \\
November & 330 & 159 & 48 \\
Desember & 330 & 125 & 38 \\
\hline
\end{tabular}

Sumber : Bali Nyuh Gading villa, 2014 
Pada Tabel 2 dapat dilihat tingkat hunian kamar pada BNG villa dari bulan Januari-Desember 2014 mengalami fluktuasi. Misalnya, pada bulan April kamar-kamar yang terjual dalam satu bulan paling sedikit hanya 57 kamar, hal ini disebabkan bulan tersebut merupakan masa sepi (low season). Pada bulan Juli, Agustus, September, dan Oktober jumlah kamar yang tersedia sudah stabil menurut banyaknya hari dalam 1 bulan dan kamar yang terjual paling banyak karena pada bulan - bulan tersebut merupakan masa ramai (high season).

Kegiatan promosi yang dilakukan oleh BNG Villa untuk tahun 2014 melakukan kegiatan promosi, yaitu dengan menggunakan media periklanan untuk menyampaikan informasi baik lewat brosur, website, internet, email, dan sales call.

Pelayanan sangat diutamakan oleh BNG Villa dalam memuaskan konsumen, sehingga akan kembali menggunakan BNG Villa sebagai tempat menginap dan ini agar terus ditingkatkan pada tahun 2015. Lingkungan fisik, seperti bangunan yang kokoh, kenyamanan ruangan, arsitektur bernuansa alam Bali, peralatan penunjang, penantaan kebun, serta lahan parkir yang luas menjadi kelebihan BNG Villa dalam upaya memperoleh konsumen dan akan terus ditingkatkan pada tahun 2015. Kenyamanan dan rasa aman memegang peranan penting dalam kepuasan konsumen.

Proses manajemen administrasi dari BNG Villa bagi para wisatawan yang akan menginap relatif sederhana dan mudah. Wisatawan asing umumnya menyerahkan prasyarat/bukti reservation seperti voucher agent, paspor dan untuk wisatawan lokal menyerahkan KTP dan SIM, sehingga para tamu mendapatkan kemudahan dan tidak berbelit-belit dalam proses manajemen administrasi. Keadaan ini akan dipertahankan dan ditingkatkan untuk tahun 2015 mendatang.

Bidang keuangan meliputi laba yang diperoleh untuk tahun 2014 cukup memuaskan, karena jumlah tamu yang menginap tergolong stabil, hasil laba didapat dengan cara mengurangkan pendapatan dengan pengeluaran. Dari hasil tersebut didapatkan bahwa laba perusahaan pada tahun 2014 sangat baik dan untuk konsumen yang menggunakan travel harus membayar paling lama dua minggu setelah meninggalkan villa.

Cash flow dari BNG Villa pada tahun 2014 sangat baik bahkan 10\% dari laba disisihkan untuk keperluan lain yang tidak terduga. BNG Villa akan berusaha mempertahankan dan meningkatkannya untuk tahun 2015 . Bidang sumber daya manusia (SDM) mencakup kualitas karyawan BNG Villa pada tahun 2014 sangat baik karena 80\% dari karyawannya adalah lulusan sekolah perhotelan sedangkan sisanya berpendidikan minimal SMU. Pada tahun 2015 mendatang, BNG Villa akan memberikan kesempatan kepada karyawan untuk meningkatkan diri agar lebih berkualitas dan cekatan dalam melaksanakan tugas dengan mengadakan pelatihan-pelatihan. 
Struktur organisasi BNG Villa sangat sederhana dengan sistem jabatan rangkap. Karyawan dapat belajar pada bidang-bidang lain, dapat menghemat tenaga dan pada saat tamu sedang sepi, villa tidak dirugikan dengan adanya karyawan tidak efektif, tetapi kelemahannya adalah pekerjaan yang dilakukan cenderung susah untuk dipertanggungjawabkan, karena karyawan tidak menguasai salah satu bidang pekerjaan.

\subsection{Kondisi Faktor Eksternal BNG Villa Tahun 2014 dan Prediksi 2015}

Hasil pengamatan menunjukkan kondisi faktor eksternal BNG Villa tahun 2014 dan prediksi tahun 2015 adalah pada lingkungan politik, situasi keamanan Bali yang berada dalam kondisi yang stabil. Tetapi, situasi keamanan pernah terganggu dengan terjadinya peledakan bom di Legian 2002 yang mengakibatkan menurunnya tingkat kedatangan wisatawan ke Bali. Banyaknya terjadi bencana alam, seperti gelombang tsunami, banjir dan tanah longsor juga berpengaruh terhadap jumlah kedatangan wisatawan. Pada tahun 2015 diharapkan pemerintah terus menggalakkan program pariwisata untuk memulihkan kondisi pariwisata.

Kebijakan pemerintah yang sangat mempengaruhi kegiatan BNG Villa adalah peraturan mendirikan perusahaan, kebijakan untuk memperoleh visa. Pada tahun-tahun mendatang BNG Villa berharap pemerintah akan lebih memperhatikan masalah pembuangan limbah agar lingkungan sekitar lebih terjaga.

Lingkungan ekonomi berkaitan dengan nilai tukar mata uang menjadi indakator faktor eksternal terutama nilai rupiah terhadap dolar Amerika yang mulai berangsur-angsur membaik atau stabil, berdampak positif terhadap perekonomian. Nilai rupiah yang semakin membaik akan berpengaruh terhadap tingkat pendapatan masyarakat terutama yang berkecimpung dalam dunia pariwisata. Hal ini menjadi dampak positif terhadap biaya-biaya operasional perusahan khususnya jasa villa, karena kegiatan operasional dapat berjalan dengan lancar. Pada tahun 2015 diharapkan kondisi nilai tukar rupiah terhadap dolar Amerika akan terus membaik sehingga perekonomian menjadi stabil.

Lingkungan sosial budaya sangat mempengaruhi kegiatan usaha jasa villa karena budaya masyarakat setempat mempengaruhi aktivitas penggunaan villa. Teknologi berkembang saat ini yang mendukung kegiatan operasional BNG Villa antara lain Wifi, TV cable, AC, plumbing (pipa pembuangan air). Tingkat persaingan dalam usaha jasa villa sangat tinggi. Banyaknya bermunculan usaha sejenis membuat BNG Villa semakin terpacu untuk memberikan pelayanan yang terbaik bagi pelanggannya serta meningkatkan fasilitas yang diberikan.

Berikut ini merupakan penjelasan nilai dan posisi dari faktor internal 
dan faktor eksternal BNG Villa untuk masa sekarang (tahun 2014) dan masa mendatang (tahun 2015) sebagai berikut:

\subsection{Nilai Internal dan Faktor Eksternal BNG Villa Tahun 2014 dan 2015}

Berikut ini diuraikan nilai faktor internal dan eksternal BNG Villa untuk tahun 2014 dan tahun 2015. Data diolah berdasarkan hasil penelitian kuesioner yang diedarkan kepada wisatawan yang menginao di BNG Villa.

Tabel 3 menunjukka penilaian responden terhadap indikator faktor internal dan eksternal BNG Villa, sehingga diketahui pengaruhnya terhadap perusahaan untuk masa sekarang (tahun 2014) dan satu tahun mendatang (tahun 2015) yang dapat dijelaskan sebagai berikut:

Faktor internal BNG Villa untuk satu tahun mendatang mengalami perubahan nilai dan posisi, di mana indikator produk yang ditawarkan nilainya meningkat dari 2,30 menjadi 3,33, sehingga posisinya berubah dari kelemahan menjadi kekuatan bagi perusahaan, indikator harga yang ditetapkan nilai dan posisinya tidak berubah sebesar 3,33 tetap menjadi kekuatan bagi perusahaan, indikator saluran distribusi nilainya naik dari 3,oo menjadi 3,33 tetap menjadi kekuatan bagi perusahaan, indikator promosi yang dilakukan tetap menjadi kelemahan bagi perusahaan dengan nilai dari 2,00 menjadi 2,33, indikator pelayanan, lingkungan fisik, proses manajemen, kualitas sumber daya manusia tetap menjadi kekuatan bagi perusahaan dengan nilai sebesar 3,33, indikator laba bersih tetap menjadi kekuatan bagi perusahaan dengan perubahan nilai dari 3,00 menjadi 3,33, indikator cash flow mengalami kenaikan nilai dan tetap merupakan kekuatan dengan nilai 2,67 menjadi 3,33 dan indikator struktur organisasi mengalami perubahan nilai dan posisi dari kelemahan menjadi kekuatan 2,30 menjadi 2,67.

Faktor eksternal BNG Villa untuk tahun sekarang (tahun 2014) dan untuk satu tahun mendatang (tahun 2015) mengalami perubahan nilai dan posisi, dimana indikator situasi keamanan di Bali mengalami perubahan nilai dari 2,33 menjadi 3,oo dari ancaman menjadi peluang bagi perusahaan, indikator kebijakan pemerintah juga mengalami perubahan dari ancaman menjadi peluang dengan perubahan nilai dari 2,33 menjadi 2,67, indikator nilai tukar mata uang tidak mengalami perubahan posisi tetapi mengalami perubahan nilai dari 3,00 menjadi 2,67, indikator budaya masyarakat setempat berubah menjadi ancaman bagi perusahaan dengan nilai dari 2,67 menjadi 2,33, indikator teknologi yang dipakai oleh villa tetap menjadi peluang dengan perubahan nilai dari 3,oo menjadi 3,33, indikator persaingan antar villa tidak mengalami perubahan nilai dan posisi, tetap menjadi ancaman bagi perusahaan dengan nilai 2,00. 
Tabel 3 Nilai dan Posisi Faktor Internal dan Faktor Eksternal BNG Villa Tahun 2014 dan 2015

\begin{tabular}{|c|c|c|c|c|c|}
\hline \multirow{2}{*}{ No. } & \multirow{2}{*}{ Indikator } & \multicolumn{2}{|c|}{ Tahun 2014} & \multicolumn{2}{|c|}{ Tahun 2015} \\
\hline & & Nilai & Posisi & Nilai & Posisi \\
\hline \multicolumn{6}{|c|}{ Faktor Internal } \\
\hline 1 & Produk yang ditawarkan & 2,3 & Lemah & 3,33 & Kuat \\
\hline 2 & Harga & 3,33 & Kuat & 3,33 & Kuat \\
\hline 3 & Saluran distribusi & 3 & Kuat & 3,33 & Kuat \\
\hline 4 & Promosi yang dilakukan & 2 & Lemah & 2,3 & Lemah \\
\hline 5 & Pelayanan & 3,33 & Kuat & 3,33 & Kuat \\
\hline 6 & Lingkungan fisik & 3,33 & Kuat & 3,33 & Kuat \\
\hline 7 & Proses manajemen & 3,33 & Kuat & 3,33 & Kuat \\
\hline 8 & Laba Bersih & 3 & Kuat & 3,33 & Kuat \\
\hline 9 & Cash Flow & 2,67 & Kuat & 3,33 & Kuat \\
\hline 10 & Kualitas sumber daya manusia & 3,33 & Kuat & 3,33 & Kuat \\
\hline 11 & Struktur organisasi & 2,3 & Lemah & 2,67 & Kuat \\
\hline \multicolumn{6}{|c|}{ Faktor Eksternal } \\
\hline 1 & Situasi keamanan di Bali & 2,33 & Ancaman & 3 & Peluang \\
\hline 2 & Kebijakan pemerintah & 2,33 & Ancaman & 2,67 & Peluang \\
\hline 3 & Nilai tukar mata uang & 3 & Peluang & 2,67 & Peluang \\
\hline 4 & Budaya masyarakat setempat & 2,67 & Peluang & 2,33 & Ancaman \\
\hline 5 & Teknologi yang dipakai oleh villa & 3 & Peluang & 3,33 & Peluang \\
\hline 6 & Persaingan antar villa & 2 & Ancaman & 2 & Ancaman \\
\hline
\end{tabular}

Sumber: Data diolah dari hasil penelitian, 2014

\subsection{Strategi Pemasaran dan Diagram Analisis SWOT}

Penilaian faktor internal dan faktor eksternal yang telah dianalisis dan telah diperoleh hasilnya selanjutnya dimasukkan ke dalam Diagram Analisis SWOT. Hasil penilaian dari para responden menunjukkan posisi strategi dari BNG Villa pada saat ini (tahun 2014) untuk faktor internalnya mendapat nilai sebesar 2,87 dan untuk faktor eksternalnya (tahun 2014) mendapat nilai sebesar 2,37. Kondisi untuk satu tahun mendatang (tahun 2015) faktor internal perusahaan mendapat nilai sebesar 3,22 dan untuk faktor eksternalnya mendapat nilai sebesar 2,68.

Letak dan posisi strategi dari BNG Villa baik untuk masa sekarang (tahun 2014) maupun untuk masa mendatang (tahun 2015) terdapat pada diagram Analisis SWOT pada Gambar 1.

Berdasarkan diagram di atas maka dapat digambarkan bahwa posisi dari BNG Villa pada Diagram Analisis SWOT untuk 2014 berada pada sel dua, yaitu pada strategi diversifikasi, dimana di dalam strategi tersebut perusahaan dapat memanfaatkan kekuatan-kekuatan dan peluang yang dimiliki perusahaan untuk mengatasi kelemahan dan ancaman yang dihadapi, misalnya dengan menambah fasilitas-fasilitas baru, meningkatkan promosi atau menambah jumlah karyawan. Pada tahun 2015 mendatang, di dalam diagram SWOT perusahaan berada pada sel pertama yaitu pada sel 
Posisi Perusahaan Pada Diagram Analisis SWOT

\begin{tabular}{|c|c|c|c|c|}
\hline SWOT & & & $\begin{array}{c}\text { Lingkungan } \\
\text { Internal }\end{array}$ & \\
\hline \multirow{4}{*}{$\begin{array}{c}\text { Lingkungan } \\
\text { Eksternal }\end{array}$} & \multirow[b]{2}{*}{ Peluang } & \multirow[b]{2}{*}{4} & Kelemahan & Kekuatan \\
\hline & & & $\begin{array}{c}\text { Sel 3 } \\
\text { Strategi } \\
\text { berbenah diri }\end{array}$ & $\begin{array}{c}\text { Sel } 1 \\
\text { Strategi agresif }\end{array}$ \\
\hline & & & ..................... & $\ldots \ldots \ldots \ldots$ \\
\hline & Ancaman & 2,5 & $\begin{array}{l}\text { Sel } 4 \\
\text { Strategi defen- } \\
\text { sive }\end{array}$ & $\begin{array}{c}\text { Sèl 2 } \\
\vdots \\
\begin{array}{c}\text { Strategi divệrsi- } \\
\text { fikasi }\end{array}\end{array}$ \\
\hline & & & & 2,5 \\
\hline
\end{tabular}

Sumber : Data Diolah, 2014

Keterangan:

*** Posisi BNG Villa untuk masa sekarang (tahun 2014)

* = Posisi BNG Villa untuk masa mendatang (tahun 2015)

strategi agresif, dimana dalam strategi tersebut dapat lebih meningkatkan dan memanfaatkan kekuatan dan peluang yang ada, mempelajari dan membenahi berbagai kelemahan dan ancaman yang ada agar dapat dimanfaatkan untuk lebih bisa diubah menjadi suatu kekuatan dan peluang bagi perusahaan, sehingga akan dapat tercapai tujuan perusahaan yaitu memberikan pelayanan yang terbaik untuk mencapai kepuasan para konsumen dan menjadi tender dalam persaingan.

\section{Simpulan}

Dengan melihat situasi dan kondisi yang demikian, maka alternatif strategi yang sebaiknya digunakan oleh BNG Villa untuk tahun 2015 mendatang adalah strategi agresif. Strategi agresif ini dapat diterapkan dengan melakukan pengembangan produk (inovasi produk), pelatihan dan pengembangan karyawan agar karyawan memiliki kualitas yang baik dalam melayani para konsumen, menggencarkan promosi agar produk dari perusahaan dikenal oleh para konsumen. BNG Villa harus memiliki kemampuan untuk menerapkan strtegi agresif yang akan digunakan baik dengan cara menambahkan fasilitas-fasilitas kamarvilla dan kelengkapannya, fasilitas makanan dan minuman serta fasilitas-fasilitas lainnya agar BNG Villa terus dapat tumbuh dan berkembang sehingga selalau dapat bersaing di pasaran.

Dari seluruh uraian di atas terlihat bahwa BNG Villa untuk tahun ini (tahun 2014) memiliki beberapa perbedaan kondisi faktor internal dan eksternal perusahaan. Berikut ini adalah beberapa kekuatan, kelemahan, peluang dan ancaman yang dihadapi oleh BNG Villa untuk tahun ini (tahun 
2014) dan untuk tahun mendatang (tahun 2015) adalah:

a. Kekuatan yang dimiliki oleh BNG Villa untuk saat ini (tahun 2014) adalah terletak pada indikator harga yang ditetapkan, saluran distribusi, indikator pelayanan, lingkungan fisik, proses manajemen, kualitas sumber daya manusia, laba bersih, cash flow. Kelemahan yang dimiliki oleh BNG Villa terletak pada indikator produk yang ditawarkan, promosi yang dilakukan dan struktur organisasi.

b. Peluang yang dimiliki oleh BNG Villa untuk tahun sekarang (tahun 2014) adalah nilai tukar mata uang, budaya masyarakat setempat, teknologi yang dipakai oleh villa. Ancaman yang akan dihadapi oleh BNG Villa adalah situasi keamanan di Bali, kebijakan pemerintah persaingan antar villa

c. Strategi yang sebaiknya diterapkan oleh BNG Villa untuk masa mendatang (Tahun 2015) adalah strategi yang memaksimalkan kekuatan yang dimiliki, memanfaatkan peluang-peluang yang ada dengan pilihan alternatif strategi yaitu strategi agresif. Strategi agresif ini dilakukan dengan cara melakukan pengembangan produk (inovasi produk) villa, pelatihan dan pengembangan karyawan agar karyawan lebih berkualitas dalam melayani tamu, melakukan promosi yang lebih gencar dan melakukan peningkatan pada indikator-indikator lainnya.

\section{Saran}

Pada masa yang akan datang (tahun 2015) hendaknya perusahaan menerapkan strategi agresif. Untuk mendukung strategi agresif yang akan ditetapkan oleh perusahaan, maka dapat dilakukan hal-hal sebagai berikut:

Pada tahun 2015 mendatang perusahaan perlu menambah fasilitasfasilitas yang disediakan misalnya dengan menambah fasilitas kamar villa dan kelengkapannya, fasilitas makanan dan minuman, dan menambah fasilitas-fasilitas yang dibutuhkan oleh para konsumen sehingga BNG Villa dapat menandingi para pesaingnya.

Menambah jumlah karyawan agar mengurangi jabatan rangkap, meningkatkan kemampuan, kualitas dan mutu karyawan dengan mengadakan pelatihan-pelatihan, melakukan promosi yang lebih gencar karena pendapatan/ laba yang akan diperoleh perusahaan sangat dipengaruhi oleh kemampuan dan kualitas karyawan dalam memasarkan produk perusahaan dan memberikan pelayanan yang maksimal kepada para tamu/konsumen.

\section{Ucapan Terima Kasih}

Penulis mengucapkan terimakasih kepada Prof. Dr. I Nyoman Darma Putra, M.Litt selaku Ketua Program Studi Magister (S2) Kajian Pariwisata, Program Pascasarjana Universitas Udayana. Prof. Dr. I Made Sukarsa, SE. 
MS selaku pembimbing I yang telah banyak memberikan bimbingan dan masukan dalam penyusunan tesis ini. Prof. Dr. Ir. Made Antara, MS selaku pembimbing II. Prof. Dr. I Nyoman Sirtha, SH., MS, Dr. Ir. Syamsul Alam Paturusi, MSP, dan Prof. Dr. I Gde Semadi Astra selaku Penguji. Terima kasih pada pemilik villa, Dr. I Putu Gde Wardhiana, Sp.OG ( K), Para Responden dan seluruh karyawan dari BNG Villa yang sudah memberikan waktunya dalam menyelesaikan skripsi ini sampai selesai. Terima kasih yang sebesarbesarnya penulis ucapkan kepada kedua orang tua terutama Drs. Putu Ardhana, M.Par yang telah memberikan semangat dan dukungan moral demi terselesaikannya tesis ini. Rasa terima kasih juga penulis ucapkan kepada Luh Gde Siska Dewi Gelgel dan Putu Dian Krisna Keyla Nathania yang tidak pernah lelah mendukung serta memberikan motivasi kepada penulis. Dan seluruh teman-teman yang tidak dapat penulis sebutkan satu per satu yang telah membantu secara langsung maupun tidak langsung sehingga tesis ini bisa terselesaikan.

\section{Daftar Pustaka}

balivilla-association.org .2016. http://www.balivilla-association.org/member/howto-become-a-member.html Diakses 4 Juli 2016.

Boyd, Harper W, dkk 2000. Manajemen Pemasaran : Suatu Pendekatan Strategis dengan Orientasi Global. Jilid 1. Jakarta:Erlangga.

Budiasa, I Made. 2009. Analisis Perencanaan Strategis Daya Tarik Wisata Bali Orchid Garden. Tesis Sarjana Program Pascasarjana Universitas Udayana, Denpasar.

David, Fred R. (Alih Bahasa Oleh Alexander Sindoro). 2002. Manajemen Strategis: Konsep. Jakarta: PT.Prenhallindo.

David, Fred R. 2006. Strategic Management: Concepts and Cases. 10 ${ }^{\text {th }}$ Edition. (managemen Strategis: Konsep-Konsep dan Kasus). Edisi Bahasa Indonesia. Jakarta: Salemba Empat.

Dinas Pariwisata Propinsi Bali (2010). Departemen Kebudayaan dan Pariwisata Republik Indonesia. 2009. Undang-undang Republik Indonesia Nomor 10 Tahun 2009 Tentang Kepariwisataan.

Dwiddharma Pradnyaputra, A.A. Ngr. 2005. Formulasi Strategi Korporat pada Three Brothers Bungalows di Legian - Kuta. Tesis Sarjana Jurusan Magister Manajemen pada Fakultas Ekonomi Universitas Udayana, Denpasar.

Glossary Sihite. 1997. Manajemen Pariwisata. Jakarta: Gramedia Pustaka Utama.

Hitchcock, Michael dan I Nyoman Darma Putra. 2007. Tourism Development and Terrorism in Bali. London: Ashgate.

Hitt, Michael A, Ireland, dan Hoskisson. 2001. Manajemen Strategis: Daya Saing dan Globalisasi ; Konsep. Jakarta: Salemba Empat.

Hunger, David J. dan Wheelen, Thomas L. 2001. Manajemen Strategis. Yogyakarta: Andi. 
Husein Umar. 2000. Riset Pemasaran dan Prilaku Konsumen. Jakarta: Gramedia Pustaka Utama.

Jennings, Gayle. 2001. Tourism Research. Queensland: John Wiley \& Sons Australia Ltd.

Kotler, Philip. 2002. Manajemen Pemasaran. Edisi Millenium. Jakarta: Prenhallindo. Kusmayadi dan Sugiarto, Endar. 2000. Metodologi Penelitian Dalam Bidang Kepariwisataan. Jakarta: PT. Gramedia Pustaka Utama.

Pearce dan Robinson. 1997. Manajemen Stratejik, Formulasi, Implementasi dan Pengendalian. Jakarta: Binarupa Aksara.

Rangkuti, Freddy. 2001. Riset Pemasaran. Cetakan Keempat. Jakarta: Gramedia Pustaka Utama.

Robert Sucipto, 2011. Formulasi Strategi Pemasaran The Radiant Hotel and Spa. Tesis Sarjana Jurusan Magister Manajemen pada Fakultas Ekonomi Universitas Udayana, Denpasar.

Salim, Peter. 2002. Manajemen Kantor Depan Hotel. Jakarta: Gramedia Pustaka Utama.

Sri Dewi Wahyuni, Ni Kadek. 2005. Perumusan Strategi Perusahaan Untuk Menghadapi Pesaing Pada Tresna Yoga Bungalow. Skripsi Sarjana Jurusan Manajemen pada Fakultas Ekonomi Universitas Udayana, Denpasar.

Wahyudi Agustianus Sri. 1997. Manajemen Strategik, Pengantar Proses Berfikir strategik. Jakarta: Bina Rupa Aksara

Wardana, A.A. Ngurah Agung. 2005. Formulasi Strategi Legian Village Hotel dan Spa di Legian Kuta Bali. Tesis Sarjana Jurusan Magister Manajemen pada Fakultas Ekonomi Universitas Udayana, Denpasar.

Wheelen, Thomas L. and Hunger, J. David. 2000. Strategic Management and Business policy: Entering 21 st Century Global Society. Seventh Edition. New Jersey: Addison Wesly Longman.

Yoeti, O A. 2001. Strategi Pemasaran Hotel. Jakarta: PT. Gramedia Pustaka Utama.

\section{Profil Penulis}

Made Adi Krisna Dwipayana, S.E. adalah mahasiswa Magister Kajian Pariwisata Universitas Udayana. Ia menyelesaikan program studi Strata I di Fakultas Ekonomi Universitas Udayana. Pengalaman yang dimiliki adalah bekerja selama 7 tahun di RS.BaliMed dan saat ini menjabat sebagai kepala Divisi Pemasaran dan Hubungan Pelanggan di Rumah Sakit BaliMed. Dengan pertimbangan bahwa pendidikan adalah modal untuk masa depan, Krisna menempuh pendidikan magister kajian pariwisata untuk menambah ilmu pengetahuan di mana akan semakin beragam ilmu yang dimilikinya di bidang ekonomi, kesehatan, dan pariwisata. 